\title{
Microwave Spectrum, Structure, and Dipole Moment of Difluorophosphine Borane*
}

\author{
John P. Pasinski and Robert L. Kuczkowski \\ Department of Chemistry, The University of Michigan, Ann Arbor, Michigan 48104
}

(Received 16 September 1970)

\begin{abstract}
The structure of difluorophosphine borane $\left(\mathrm{HF}_{2} \mathrm{P}-\mathrm{BH}_{3}\right)$ has been determined from the microwave spectra of six isotopic species. The expected staggered conformation and $C_{s}$ symmetry have been confirmed. The structural parameters are: $d(\mathrm{PH})=1.409 \pm 0.004 \dot{\mathrm{A}} ; d(\mathrm{PF})=1.552 \pm 0.006 \dot{\mathrm{A}} ; d(\mathrm{~PB})=1.832 \pm$ $0.009 \dot{\mathrm{A}} ; d\left(\mathrm{BH}_{a}\right)=1.226 \pm 0.005 \dot{\mathrm{A}} ; d\left(\mathrm{BH}_{s}\right)=1.200 \pm 0.007 \dot{\mathrm{A}} ; \angle \mathrm{H}_{a} \mathrm{BH}_{a}=112.7 \pm 0.5^{\circ} ; \angle \mathrm{H}_{a} \mathrm{BH}_{s}=115.9 \pm$ $0.4^{\circ} ; \angle \mathrm{FPF}=100.0 \pm 0.5^{\circ} ; \angle \mathrm{FPH}=98.62 \pm 0.25^{\circ} ; \angle \mathrm{BPF}=117.7 \pm 0.3^{\circ}$. Two angles $\left(\mathrm{PBH}_{s}=109.9 \pm 0.3^{\circ} ;\right.$ $\mathrm{PBH}_{a}=99.89 \pm 0.26^{\circ}$ ) indicate a tilt of the borane group away from the fluorine atoms. The value of the dipole moment obtained from Stark splittings is $2.504 \pm 0.030 \mathrm{D}$. A range for the barrier to internal rotation is estimated as $3600-4500 \mathrm{cal} / \mathrm{mole}$. The change in structural parameters of $\mathrm{HF}_{2} \mathrm{PBH}_{3}$ compared to similar compounds, the stability of $\mathrm{HF}_{2} \mathrm{PBH}_{3}$ towards dissociation, and the tilted borane group are discussed.
\end{abstract}

\section{INTRODUCTION}

Difluorophosphine borane $\left(\mathrm{HF}_{2} \mathrm{P}-\mathrm{BH}_{3}\right)$ was initially prepared and characterized by Rudolph and Parry. ${ }^{1}$ These investigators noted that the compound was quite stable; no evidence of dissociation to $\mathrm{HF}_{2} \mathrm{P}$ and $\mathrm{B}_{2} \mathrm{H}_{6}$ was detected in contrast to $\mathrm{F}_{3} \mathrm{P}-\mathrm{BH}_{3}$ and $\mathrm{H}_{3} \mathrm{P}-\mathrm{BH}_{3}$, both of which are highly dissociated at room temperature.

The compound is also related to $\mathrm{HF}_{2} \mathrm{P},{ }^{2} \mathrm{HF}_{2} \mathrm{PO}{ }^{3}$ and $\mathrm{F}_{3} \mathrm{P}-\mathrm{BH}_{3}{ }^{4}$ as well as to other fluorophosphine and phosphorus-boron adducts with known structures. Consequently, a study of the compound was undertaken in order to relate its structure and stability to analogous compounds.

The results of the investigation indicate a staggered conformation with a plane of symmetry. Two structural features seem most noteworthy. First, the P-B bond length of $\mathrm{HF}_{2} \mathrm{P}-\mathrm{BH}_{3}(1.832 \pm 0.009 \AA)$ is essentially identical to that of $\mathrm{F}_{3} \mathrm{P}-\mathrm{BH}_{3}(1.836 \pm 0.012 \AA){ }^{4}$ Second, the borane group is tilted away from the fluorine atoms; the two PBH angles differ by approximately $10^{\circ}$. These structural features are analyzed more fully in the Discussion section.

\section{EXPERIMENTAL}

The $\mathrm{HF}_{2} \mathrm{P}-\mathrm{BH}_{3}$ was prepared ${ }^{1}$ by reacting $\mathrm{HF}_{2} \mathrm{P}^{5}$ and $\mathrm{B}_{2} \mathrm{H}_{6}$. The spectra of both $\mathrm{HF}_{2} \mathrm{P}-{ }^{11} \mathrm{BH}_{3}$ and $\mathrm{HF}_{2} \mathrm{P}-{ }^{10} \mathrm{BH}_{3}$ were obtained with this sample. The $\mathrm{DF}_{2} \mathrm{P}-\mathrm{BH}_{3}$ was prepared by reacting pure $\mathrm{DF}_{2} \mathrm{P}$ and $\mathrm{B}_{2} \mathrm{H}_{6}$. The $\mathrm{HF}_{2} \mathrm{P}-\mathrm{BD}_{3}$ was prepared by reacting $\mathrm{HF}_{2} \mathrm{P}$ and pure $\mathrm{B}_{2} \mathrm{D}_{6}$. The $\mathrm{HF}_{2} \mathrm{P}-\mathrm{BH}_{2} \mathrm{D}$ was prepared by reacting $\mathrm{HF}_{2} \mathrm{P}$ with a gaseous mixture consisting of two parts $\mathrm{B}_{2} \mathrm{H}_{6}$ and one part $\mathrm{B}_{2} \mathrm{D}_{6}$. The diborane mixture was allowed to equilibrate ${ }^{6}$ for 1 day prior to reaction with $\mathrm{HF}_{2} \mathrm{P}$. This stoichiometry gave a mixture consisting of $44 \% \mathrm{HF}_{2} \mathrm{P}-\mathrm{BH}_{2} \mathrm{D}, 30 \% \mathrm{HF}_{2} \mathrm{P}-$ $\mathrm{BH}_{3}, 22 \% \quad \mathrm{HF}_{2} \mathrm{P}-\mathrm{BHD}_{2}$, and $4 \% \mathrm{HF}_{2} \mathrm{P}-\mathrm{BD}_{3}$. The spectra of both $\mathrm{HF}_{2} \mathrm{P}-\mathrm{BH}_{2} \mathrm{D}_{s}(15 \%)$ and $\mathrm{HF}_{2} \mathrm{P}-\mathrm{BH}_{2} \mathrm{D}_{a}$ $(29 \%)$ were obtained with this sample.

The spectra were measured with a Stark-modulation microwave spectrometer which employed $80-\mathrm{KHz}$ square wave modulation. ${ }^{2}$ All measurements were made at approximately $-78^{\circ} \mathrm{C}$ unless otherwise noted. The Stark measurements were made with a precision $\mathrm{dc}$ power supply (Fluke, Model 412B). The effective guide spacing was determined by using the $0 \rightarrow 1$ transition of OCS $(\mu=0.7152 \mathrm{D})$ ?

TABLE I. Frequencies (megahertz) of observed rotational transitions.

\begin{tabular}{|c|c|c|c|c|}
\hline \multirow[b]{2}{*}{ Transition } & \multicolumn{2}{|c|}{$\mathrm{HF}_{2} \mathrm{P}-{ }^{11} \mathrm{BH}_{3}$} & \multicolumn{2}{|c|}{$\mathrm{HF}_{2} \mathrm{P}-{ }^{10} \mathrm{BH}_{3}$} \\
\hline & $\mathrm{Obs}^{\mathrm{a}}$ & $\Delta \nu \mathrm{b}$ & Obs & $\Delta v$ \\
\hline $1_{10} \rightarrow 2_{11}$ & 21665.83 & 0.10 & 22545.7 & 0.27 \\
\hline $1_{11} \longrightarrow 2_{12}$ & 17458.47 & 0.32 & & \\
\hline $1_{11} \rightarrow 2_{21}$ & 29230.69 & -0.32 & 29508.54 & -0.13 \\
\hline $1_{01} \rightarrow 2_{11}$ & 25590.04 & 0.03 & 26371.9 & 0.35 \\
\hline $1_{10} \rightarrow 2_{2 \mathrm{C}}$ & 28184.99 & -0.42 & (28 519.08$)$ & -0.01 \\
\hline $2_{20} \rightarrow 3_{21}$ & $(32509.46)$ & 0.00 & $\left(\begin{array}{ll}34 & 043.03\end{array}\right)$ & 0.02 \\
\hline $2_{02} \rightarrow 3_{03}$ & 26176.58 & 0.24 & & \\
\hline $211 \rightarrow 3_{12}$ & 31556.05 & -0.03 & 32624.2 & 0.55 \\
\hline $22_{12} \rightarrow 3_{13}$ & 25631.36 & 0.25 & 26386.8 & 0.37 \\
\hline $22_{21} \rightarrow 3_{22}$ & $\left(\begin{array}{ll}29 & 342.90\end{array}\right)$ & 0.00 & $\left(\begin{array}{ll}30 & 431.79\end{array}\right)$ & 0.05 \\
\hline $2_{02} \rightarrow 3_{12}$ & $(38642.33)$ & -0.01 & & \\
\hline $3_{03} \rightarrow 4_{04}$ & 33680.79 & 0.23 & 34551.15 & 0.55 \\
\hline $3_{13} \rightarrow 4_{14}$ & 33507.15 & 0.44 & 34435.98 & 0.53 \\
\hline
\end{tabular}

a Transitions in parentheses were used to calculate rotational constants. Experimental uncertainty: transitions in parentheses, $0.10 \mathrm{MHz}$ unless otherwise indicated; transitions listed to $0.01 \mathrm{MHz}, \pm 0.20 \mathrm{MHz}$; transitions listed to $0.1 \mathrm{MHz}, \pm 0.30 \mathrm{MHz}$.

${ }^{\mathrm{b}} \Delta \nu=\nu_{\mathrm{oba}}-\nu_{\mathrm{calc}}$.

\section{GROUND-STATE SPECTRA}

The rotational transitions assigned to the six isotopic species of $\mathrm{HF}_{2} \mathrm{P}-\mathrm{BH}_{3}$ are given in Tables I-III. Both " $a$ "- and " $c$ "-type transitions were observed. No splittings due to boron quadrupole or internal rotation were observed. The rotational constants, moments of inertia, and the quantity $\left(I_{A}+I_{C}-I_{B}\right)$ are given in Table IV. Since the molecule has a plane of symmetry, the quantity $\left(I_{A}+I_{C}-I_{B}\right)$ should remain 
TABLE II. Frequencies (megahertz) of observed rotational transitions.

\begin{tabular}{|c|c|c|c|c|}
\hline \multirow[b]{2}{*}{ Transition } & \multicolumn{2}{|c|}{$\mathrm{DF}_{2} \mathrm{P}-{ }^{11} \mathrm{BFH}_{3}$} & \multicolumn{2}{|c|}{$\mathrm{HF}_{2} \mathrm{P}-11 \mathrm{BD}_{3}$} \\
\hline & $\mathrm{Obs}^{\mathrm{a}}$ & $\Delta \nu^{\mathrm{b}}$ & Obs & $\Delta \nu$ \\
\hline $1_{01} \rightarrow 2_{11}$ & 24724.26 & 0.08 & 22333.40 & -0.42 \\
\hline $1_{11} \rightarrow 2_{21}$ & 28120.89 & -0.49 & & \\
\hline $1_{10} \rightarrow 2_{20}$ & 27155.18 & -0.57 & & \\
\hline $1_{11} \rightarrow 2_{12}$ & & & 15318.90 & 0.02 \\
\hline $1_{01} \rightarrow 2_{02}$ & & & 16315.38 & 0.06 \\
\hline $2_{21} \rightarrow 3_{22}$ & $(28779.13)$ & 0.07 & 25352.57 & -0.07 \\
\hline $2_{12} \rightarrow 3_{13}$ & 25397.73 & 0.37 & $(22660.17) \pm 0.15$ & 0.07 \\
\hline $2_{20} \rightarrow 3_{21}$ & $\left(\begin{array}{ll}31 & 648.76\end{array}\right)$ & 0.09 & $(27309.92)$ & 0.01 \\
\hline $2_{11} \rightarrow 3_{12}$ & $(30813.66)$ & 0.05 & $(27261.34)$ & 0.00 \\
\hline $2_{11} \rightarrow 3_{21}$ & 37698.22 & -0.39 & & \\
\hline $2_{02} \rightarrow 3_{12}$ & 37305.71 & -0.17 & $33 \quad 279.42$ & -0.42 \\
\hline $2_{02} \rightarrow 3_{03}$ & & & 23394.94 & -0.40 \\
\hline $3_{03} \rightarrow 4_{04}$ & 33423.20 & 0.51 & 30128.81 & 0.04 \\
\hline $3_{13} \rightarrow 4_{14}$ & 33256.91 & 0.48 & 29779.97 & 0.14 \\
\hline $3_{30} \rightarrow 4_{31}$ & & & 35451.67 & -0.77 \\
\hline $3_{12} \rightarrow 4_{13}$ & & & 35319.89 & -0.44 \\
\hline $3_{22} \rightarrow 4_{23}$ & & & 33331.14 & -0.47 \\
\hline
\end{tabular}

a See Footnote a of Table I.

essentially unchanged for isotopic substitution in the symmetry plane.

For all isotopes the assignments were substantiated by the rigid-rotor frequency fit, the observed Stark effects, the values of $\left(I_{A}+I_{C}-I_{B}\right)$, and the expected isotopic shifts. The samples of $\mathrm{DF}_{2} \mathrm{P}-\mathrm{BH}_{3}$ and $\mathrm{HF}_{2} \mathrm{P}-$ $\mathrm{BD}_{3}$ were essentially $100 \%$ enriched, making assignments easy and unambiguous. The $\mathrm{HF}_{2} \mathrm{P}-{ }^{10} \mathrm{BH}_{3}$ was studied in natural abundance; the expected $25 \%$ intensity relative to that of $\mathrm{HF}_{2} \mathrm{P}-{ }^{11} \mathrm{BH}_{3}$ was observed at room temperature and $-78^{\circ} \mathrm{C}$. The following intensity checks on the $\mathrm{HF}_{2} \mathrm{P}-\mathrm{BH}_{3}, \mathrm{HF}_{2} \mathrm{P}-\mathrm{BH}_{2} \mathrm{D}$ mixture were made at $-78^{\circ} \mathrm{C}$. The $\mathrm{HF}_{2} \mathrm{P}-\mathrm{BH}_{2} \mathrm{D}_{a}$ was twice as abundant as $\mathrm{HF}_{2} \mathrm{P}-\mathrm{BH}_{2} \mathrm{D}_{s} ; \mathrm{HF}_{2} \mathrm{P}-\mathrm{BH}_{2} \mathrm{D}_{a}$
${ }^{b}$ See Footnote $b$ of Table I.

was as abundant as $\mathrm{HF}_{2} \mathrm{P}-{ }^{11} \mathrm{BH}_{3}$. These results were consistent with the enrichment of the partially deuterated sample.

\section{DIPOLE MOMENT}

The second-order Stark effect was measured for the transitions listed in Table V. From the Stark coefficients the following values were determined: $\left|\mu_{a}\right|=$ $1.826 \pm 0.010 \mathrm{D},\left|\mu_{c}\right|=1.714 \pm 0.020 \mathrm{D},\left|\mu_{\text {tot }}\right|=2.504 \pm$ $0.030 \mathrm{D}$. The dipole moment makes an angle of $43.05^{\circ}$ with the " $a$ " axis. While the " $a c$ " quadrant in which the dipole moment lies was not determined, bond moment arguments support the orientation depicted in Fig. 1 (see Discussion).

TABLE III. Frequencies (megahertz) of observed rotational transitions.

\begin{tabular}{|c|c|c|c|c|}
\hline \multirow[b]{2}{*}{ Transition } & \multicolumn{2}{|c|}{$\mathrm{HF}_{2} \mathrm{P} \_11 \mathrm{BH}_{2} \mathrm{D}_{s}$} & \multicolumn{2}{|c|}{$\mathrm{HF}_{2} \mathrm{P}-{ }^{11} \mathrm{BH}_{2} \mathrm{D}_{a}$} \\
\hline & Obs $^{\mathbf{a}}$ & $\Delta \nu^{\mathrm{b}}$ & Obs & $\Delta \nu$ \\
\hline $2_{02} \rightarrow 3_{12}$ & 36414.6 & 0.84 & 36710.0 & 0.32 \\
\hline $2 \ldots 1 \rightarrow 3_{21}$ & 37198.85 & -0.31 & 37517.25 & 0.01 \\
\hline $22_{20} \rightarrow 3_{21}$ & 30445.52 & 1.06 & $(30477.02) \pm 0.15$ & 0.06 \\
\hline $2_{02} \rightarrow 3_{03}$ & 25321.25 & 0.17 & 25099.64 & 0.17 \\
\hline $2_{12} \rightarrow 3_{13}$ & 24695.99 & 0.31 & 24449.08 & 0.01 \\
\hline $2_{21} \rightarrow 3_{22}$ & 27883.3 & 0.58 & 27788.14 & -0.09 \\
\hline $3_{03} \rightarrow 4_{04}$ & $(32614.19) \pm 0.15$ & 0.07 & $\left(\begin{array}{ll}32 & 266.73\end{array}\right)$ & 0.11 \\
\hline $3_{12} \rightarrow 4_{13}$ & $(38434.17) \pm 0.15$ & 0.04 & $(38355.97)$ & 0.03 \\
\hline $3_{31} \rightarrow 4_{32}$ & 38307.55 & 0.11 & 38236.73 & -0.96 \\
\hline $3_{13} \rightarrow 4_{14}$ & 32375.85 & 0.22 & 32019.75 & -0.04 \\
\hline $3_{22} \rightarrow 4_{23}$ & $(36511.59) \pm 0.15$ & -0.04 & 36351.05 & -0.33 \\
\hline
\end{tabular}


TABLE IV. Rotational constants (megahertz) and moments of inertia (atomic mass units•square angstroms).

\begin{tabular}{|c|c|c|c|c|c|c|}
\hline & $\mathrm{HF}_{2} \mathrm{P}-{ }^{11} \mathrm{BH}_{3}$ & $\mathrm{HF}_{2} \mathrm{P}-{ }^{10} \mathrm{BH}_{3}$ & $\mathrm{DF}{ }_{2} \mathrm{P}-{ }^{11} \mathrm{BH}_{3}$ & $\mathrm{HF}_{2} \mathrm{P}-{ }^{11} \mathrm{BH}_{2} \mathrm{D}_{a}$ & $\mathrm{HF}_{2} \mathrm{P}-{ }^{11} \mathrm{BH}_{2} \mathrm{D}_{s}$ & $\mathrm{HF}_{2} \mathrm{P}-{ }^{11} \mathrm{BD}_{3}$ \\
\hline$A$ & $7762.88 \pm 0.15$ & $7769.26 \pm 0.15$ & $7455.00 \pm 0.25$ & $7653.84 \pm 0.50$ & $7544.88 \pm 0.40$ & $7283.19 \pm 1.00$ \\
\hline$B$ & $5942.38 \pm 0.10$ & $6200.78 \pm 0.15$ & $5756.40 \pm 0.10$ & $5592.50 \pm 0.10$ & $5564.89 \pm 0.10$ & $5016.88 \pm 0.10$ \\
\hline$C$ & $3838.59 \pm 0.10$ & $3943.15 \pm 0.15$ & $3836.63 \pm 0.10$ & $3670.25 \pm 0.10$ & $3729.38 \pm 0.10$ & $3434.00 \pm 0.20$ \\
\hline$I_{A}$ & $\begin{array}{l}65.1216 \\
(0.0000)^{b}\end{array}$ & $\begin{array}{l}65.0681 \\
(0.0016)\end{array}$ & $\begin{array}{l}67.8110 \\
(0.0020)\end{array}$ & $\begin{array}{l}66.0493 \\
(0.0030)\end{array}$ & $\begin{array}{c}67.0032 \\
(-0.0272)\end{array}$ & $\begin{array}{c}69.4107 \\
(-0.0516)\end{array}$ \\
\hline$I_{B}$ & $\begin{array}{l}85.0721 \\
(0.0008)\end{array}$ & $\begin{array}{l}81.5270 \\
(0.0009)\end{array}$ & $\begin{array}{l}87.8207 \\
(0.0007)\end{array}$ & $\begin{array}{l}90.3945 \\
(0.0007)\end{array}$ & $\begin{array}{c}90.8429 \\
(-0.0015)\end{array}$ & $\begin{array}{c}100.7660 \\
(-0.0015)\end{array}$ \\
\hline$I_{C}$ & $\begin{array}{c}131.6971 \\
(0.0004)\end{array}$ & $\begin{array}{c}128.2049 \\
(-0.0019)\end{array}$ & $\begin{array}{r}131.7643 \\
(0.0062)\end{array}$ & $\begin{array}{c}137.7375 \\
(-0.0024)\end{array}$ & $\begin{array}{c}135.5536 \\
(-0.0074)\end{array}$ & $\begin{array}{c}147.2135 \\
(-0.0314)\end{array}$ \\
\hline$\Delta^{\mathrm{a}}$ & 111.7466 & 111.7460 & 111.7546 & 113.3923 & 111.7139 & 115.8582 \\
\hline
\end{tabular}

${ }^{\mathrm{a}} \Delta=I_{A}+I_{C}-I_{B}$

\section{STRUCTURAL ANALYSIS}

The values of $\left(I_{A}+I_{C}-I_{B}\right)$ for the various isotopic species substantiate that a plane of symmetry exists; the isotopic shifts of the $\mathrm{HF}_{2} \mathrm{P}-\mathrm{BH}_{2} \mathrm{D}$ species are consistent only with the staggered conformation. With this symmetry established, the remaining 11 parameters were calculated in the following manner. The coordinates of the boron, the hydrogen bonded to phosphorus, and both types of hydrogen bonded to boron (in plane $H_{s}$ and out of plane $H_{a}$ ) were obtained by the substitution method of Kraitchman. ${ }^{8}$ The coordinates of the phosphorus and the fluorine atoms were obtained by the use of first and second moment equations. The coordinates of the atoms and corresponding structural parameters along with estimated experimental uncertainties are given in Tables VI and VII, respectively. This structure is illustrated in Fig. 2.

In calculating the structure in this manner, two independent checks can be made. First, the product of inertia $\left(\sum m_{i} a_{i} c_{i}\right)$ gave the reasonable value of $0.145 \mathrm{amu} \cdot \AA^{2}$. Second, the moments of inertia of all isotopic species, including the $\mathrm{HF}_{2} \mathrm{P}-\mathrm{BD}_{3}$ species which was not used in the calculation of the structure, were

TABLE V. Stark coefficients (megahertz/square volts/square centimeter) and dipole moment of $\mathrm{HF}_{2} \mathrm{P}-\mathrm{BH}_{3}$.

\begin{tabular}{ccr}
\hline \multicolumn{1}{c}{ Transition } & Observed $^{\mathbf{a}}$ & Calculated \\
\hline $2_{20} \rightarrow 3_{21}(M=1)$ & $-7.55 \times 10^{-5}$ & $-7.56 \times 10^{-5}$ \\
$2_{11} \rightarrow 3_{12}(M=2)$ & $-1.39 \times 10^{-5}$ & $-1.39 \times 10^{-5}$ \\
$2_{11} \rightarrow 3_{12}(M=1)$ & $-4.76 \times 10^{-6}$ & $-4.77 \times 10^{-6}$ \\
$2_{21} \rightarrow 3_{22}(M=1)$ & $8.15 \times 10^{-5}$ & $8.14 \times 10^{-5}$ \\
& $\left|\mu_{a}\right|=1.826 \pm 0.010 \mathrm{D}, \quad\left|\mu_{\mathrm{o}}\right|=1.714 \pm 0.020 \mathrm{D}$, \\
& $\left|\mu_{\text {tot }}\right|=2.504 \pm 0.030 \mathrm{D}$ \\
\hline
\end{tabular}

${ }^{a}$ Estimated experimental uncertainty is $1 \%$. b The numbers in parentheses indicate $\left(I_{\mathrm{obs}}-I_{\mathrm{calc}}\right)$ (atomic mass units'square angstroms).

reproduced to better than $0.1 \%$ (see Table IV). In this structural calculation, the only sign assumption that appeared ambiguous was that of the " $a$ " coordinate of the hydrogen bonded to phosphorus. Reversing its sign yielded a structure essentially identical to the above except that the $\mathrm{BPH}$ angle changed to $98.99^{\circ}$ and the FPH angle changed to $111.38^{\circ}$. This structure was rejected because the product equation was poorly satisfied $\left(\sum m_{i} a_{i} c_{i}=0.850 \mathrm{amu} \cdot \AA^{2}\right)$.

An estimate of the effect of vibrations on the structure was made by assuming that deuterium substitution caused a $0.005 \AA$ shortening of a particular bond. This produced $\mathrm{B}-\mathrm{H}$ and $\mathrm{P}-\mathrm{H}$ bond length changes of less than $0.015 \AA$; the other bond lengths remained essentially unchanged. Changes in the bond angles due to this effect were no larger than $0.20^{\circ}$.

Due to the large uncertainties associated with the $\mathrm{B}-\mathrm{H}$ bond lengths, the experimentally observed difference in these parameters $\left(\mathrm{B}-\mathrm{H}_{a}=1.226 \AA, \mathrm{B}-\mathrm{H}_{8}=\right.$ $1.200 \AA$ ) may not be real. However, the difference in

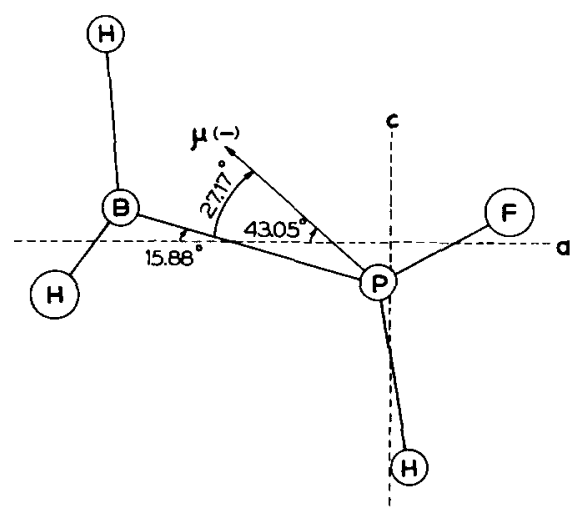

Frg. 1. Projection of $\mathrm{HF}_{2} \mathrm{P}-\mathrm{BH}_{3}$ on symmetry plane with likely orientation of the dipole moment. 
TABLE VI. Principal axis coordinates (angstroms) of $\mathrm{HF}_{2} \mathrm{P}-\mathrm{BH}_{3}{ }^{\mathrm{a}}$

\begin{tabular}{cccr}
\hline Atom & $a$ & $b$ & \multicolumn{1}{c}{$c$} \\
\hline $\mathrm{P}$ & -0.0990 & 0.0 & -0.2780 \\
$\mathrm{~B}$ & -1.8614 & 0.0 & 0.2236 \\
$\mathrm{H}_{\mathrm{a}}$ & -2.2408 & \pm 1.0205 & -0.3401 \\
$\mathrm{H}_{\mathrm{a}}$ & -1.9457 & 0.0 & 1.4207 \\
$\mathrm{H}_{\mathrm{P}}$ & 0.2469 & 0.0 & -1.6439 \\
$\mathrm{~F}$ & 0.7840 & \pm 1.1894 & 0.1858 \\
\hline
\end{tabular}

${ }^{a}$ Masses were taken from C. H. Townes and A. L. Schawlow, Microwave Spectroscopy (McGraw-Hill, New York, 1955).

the $\mathrm{PBH}$ angles $\left(\mathrm{PBH}_{s}=109.91^{\circ}, \mathrm{PBH}_{a}=99.89^{\circ}\right)$ is considerably beyond experimental uncertainty or vibrational shrinkage effects.

\section{VIBRATIONAL SATELLITE SPECTRA}

A search for the vibrational satellite spectra of $\mathrm{HF}_{2} \mathrm{P}-\mathrm{BH}_{3}$ revealed approximately 15 lines with resolvable Stark effects and intensities about $25 \%$ that of the ground-state lines. Six of the lines were fitted to a rigid-rotor spectrum (see Table VIII). The remaining data comprised two additional vibrational satellites. No exhaustive efforts were made to assign these satellites since the low-frequency vibrational spectrum of $\mathrm{HF}_{2} \mathrm{P}-\mathrm{BH}_{3}$ was recently obtained. ${ }^{9}$ This study indicated that the lowest three vibrations were at 210,221 , and $247 \mathrm{~cm}^{-1}$. From a preliminary analysis of Raman polarization measurements, the torsion has been tentatively assigned at either 221 or $247 \mathrm{~cm}^{-1}$. Since it is of interest to compare the barrier to internal rotation with other molecules, the barrier was calculated by taking these two vibrational frequencies, a threefold potential function, and assuming a borane group symmetrical about the $\mathrm{P}-\mathrm{B}$ bond $\left(I_{r}=3.918\right.$ $\left.\mathrm{amu} \cdot \AA^{2}\right)$. This procedure gave a range for the barrier of $V=3600-4500 \mathrm{cal} / \mathrm{mole}$.

\section{DISCUSSION}

The results of this structural investigation suggest three related areas for further discussion: the change

TABLE VII. Structural parameters of $\mathrm{HF}_{2} \mathrm{P}-\mathrm{BH}_{3}$.

\begin{tabular}{lllr}
\hline \multicolumn{2}{c}{ Bond lengths $(\AA)$} & \multicolumn{2}{l}{ Bond angles (Degrees) } \\
\hline$d(\mathrm{PH})$ & $1.409 \pm 0.004$ & $\mathrm{H}_{a} \mathrm{BH}_{a}$ & $112.69 \pm 0.53$ \\
$d(\mathrm{PF})$ & $1.552 \pm 0.006$ & $\mathrm{H}_{a} \mathrm{BH}_{s}$ & $115.91 \pm 0.37$ \\
$d(\mathrm{~PB})$ & $1.832 \pm 0.009$ & $\mathrm{PBH}_{s}$ & $109.91 \pm 0.27$ \\
$d\left(\mathrm{BH}_{a}\right)$ & $1.226 \pm 0.005$ & $\mathrm{PBH}_{a}$ & $99.89 \pm 0.26$ \\
$d\left(\mathrm{BH}_{s}\right)$ & $1.200 \pm 0.007$ & $\mathrm{BPH}$ & $120.10 \pm 0.55$ \\
& & $\mathrm{BPF}$ & $117.73 \pm 0.28$ \\
& & $\mathrm{FPF}$ & $100.04 \pm 0.47$ \\
& & $\mathrm{FPH}$ & $98.62 \pm 0.24$ \\
\hline \hline
\end{tabular}

in structural parameters of $\mathrm{HF}_{2} \mathrm{P}-\mathrm{BH}_{3}$ compared to similar compounds; the comparative stability of $\mathrm{F}_{3} \mathrm{P}-$ $\mathrm{BH}_{3}$ and $\mathrm{HF}_{2} \mathrm{P}-\mathrm{BH}_{3}$ towards dissociation, and the tilted borane group.

The structural parameters of several related compounds are listed in Table IX. If the structural parameters of $\mathrm{HF}_{2} \mathrm{P}$ are compared to those of the coordinated species $\mathrm{HF}_{2} \mathrm{P}-\mathrm{BH}_{3}$, the $\mathrm{P}-\mathrm{F}$ bond length decreases while the FPF and FPH angles increase for the coordinated species. A similar effect is also evident upon comparison of the structural parameters of $\mathrm{HF}_{2} \mathrm{P}$ and $\mathrm{HF}_{2} \mathrm{PO}$, which is isoelectronic with $\mathrm{HF}_{2} \mathrm{P}-\mathrm{BH}_{3}$. The changes of the structural parameters of $\mathrm{F}_{3} \mathrm{P}$ upon coordination with a borane group $\left(\mathrm{F}_{3} \mathrm{P}-\mathrm{BH}_{3}\right)$ are exactly analogous and were previously discussed by Morino et al. ${ }^{10}$ In general, the data reflect two empirical trends, namely bond lengths to phosphorus decrease and bond angles about phosphorus increase as more electronegative groups are attached. These

TABLE VIII. Vibrational satellite of $\mathrm{HF}_{2} \mathrm{P}-\mathrm{BH}_{3}$.

\begin{tabular}{ccc}
\hline \hline Transition & Obs $(\mathrm{MHz})$ & $\Delta \nu^{\text {a }}(\mathrm{MHz})$ \\
\hline $2_{20 \rightarrow 3_{21}}$ & $(32383.78 \pm 0.25) \mathrm{b}$ & -0.01 \\
$2_{02} \rightarrow 3_{03}$ & $(25156.43 \pm 0.15)$ & -0.05 \\
$2_{11 \rightarrow 3} \rightarrow 3_{12}$ & $(31488.13 \pm 0.20)$ & 0.02 \\
$2_{21} \rightarrow 3_{22}$ & $29270.85 \pm 0.30$ & 0.74 \\
$3_{03} \rightarrow 4_{04}$ & $33650.14 \pm 0.20$ & -0.42 \\
$3_{13} \rightarrow 4_{14}$ & $33466.94 \pm 0.15$ & 0.04 \\
\hline
\end{tabular}

s $\Delta \nu=\nu_{\text {obs }}-\nu_{\text {calc }}$.

b Parentheses indicate transitions used to calculate the rotational constants: $A=7783.19 \mathrm{MHz}, B=5922.29 \mathrm{MHz}, C=3834.43 \mathrm{MHz}$.

trends can be rationalized by several popular semiempirical models such as: (1) electron-pair repulsion, ${ }^{11}$ (2) hybridization changes, ${ }^{12}$ (3) $d$ orbital participation, ${ }^{13}$ (4) formal charges, or (5) valence bond resonance structures. Each of the preceding models incorporates the concept of electronegativity differences in order to rationalize systematic changes in structural parameters.

A noteworthy exception to the usual trend occurs in the comparison of the $\mathrm{P}-\mathrm{B}$ bond lengths of $\mathrm{HF}_{2} \mathrm{P}-$ $\mathrm{BH}_{3}$ and $\mathrm{F}_{3} \mathrm{P}-\mathrm{BH}_{3}$; the data indicate that this structural parameter is nearly identical for the two molecules. While it is exceptional that the $\mathrm{P}-\mathrm{B}$ bond in $\mathrm{HF}_{2} \mathrm{P}-\mathrm{BH}_{3}$ is not longer than that in $\mathrm{F}_{3} \mathrm{P}-\mathrm{BH}_{3}$ based upon the semiempirical models, it is also surprising that it is not significantly shorter based upon the greater stability of $\mathrm{HF}_{2} \mathrm{P}-\mathrm{BH}_{3}$ towards dissociation. Rudolph and Parry had previously noted this stability and had suggested that the borane group would approach more closely in $\mathrm{HF}_{2} \mathrm{P}$ than $\mathrm{F}_{3} \mathrm{P} .{ }^{1}$ To rationalize this, they postulated that $\mathrm{HF}_{2} \mathrm{P}$ was a "tighter pyramid" and that the hydrogen would release electron 
TABLE IX. Comparison of structural parameters. ${ }^{a}$

\begin{tabular}{|c|c|c|c|c|c|c|c|}
\hline & $\begin{array}{c}d(\mathrm{P}-\mathrm{F}) \\
(\AA)\end{array}$ & $\begin{array}{c}d(\mathrm{P}-\mathrm{H}) \\
(\AA)\end{array}$ & $\begin{array}{c}d(\mathrm{P}-\mathrm{B}) \\
(\AA)\end{array}$ & $\begin{array}{c}d(\mathbf{B}-\mathrm{H}) \\
(\AA)\end{array}$ & $\begin{array}{c}\angle F P F \\
\text { (degrees) }\end{array}$ & $\begin{array}{c}\angle \mathrm{FPH} \\
\text { (degrees) }\end{array}$ & $\begin{array}{c}\angle \mathrm{HBH} \\
\text { (degrees) }\end{array}$ \\
\hline $\mathrm{HF}_{2} \mathrm{P}-\mathrm{BH}_{3}$ & $1.552 \pm 0.006$ & $1.409 \pm 0.004$ & $1.832 \pm 0.009$ & $\begin{array}{l}1.226 \pm 0.005(a) \\
1.200 \pm 0.007(s)\end{array}$ & $100.04 \pm 0.50$ & $98.62 \pm 0.25$ & $\begin{array}{l}112.69 \pm 0.53 \\
115.91 \pm 0.37\end{array}$ \\
\hline $\mathrm{HF}_{2} \mathrm{P}$ & $1.582 \pm 0.002$ & $1.412 \pm 0.006$ & & & $99.0 \pm 0.2$ & $96.3 \pm 0.5$ & \\
\hline $\mathrm{F}_{3} \mathrm{P}-\mathrm{BH}_{3}$ & $1.538 \pm 0.008$ & & $1.836 \pm 0.012$ & $1.207 \pm 0.006$ & $99.83 \pm 1.00$ & & $115.07 \pm 1.00$ \\
\hline $\mathrm{F}_{3} \mathrm{P}$ & $1.570 \pm 0.001$ & & & & $97.8 \pm 0.2$ & & \\
\hline $\mathrm{HF}_{2} \mathrm{PO}$ & $1.539 \pm 0.003$ & $1.387 \pm 0.01$ & & & $99.8 \pm 0.5$ & $101.9 \pm 1.5$ & \\
\hline
\end{tabular}

${ }^{a} \mathrm{HF}_{2} \mathrm{P}-\mathrm{BH}_{3}$, this work; $\mathrm{HF}_{2} \mathrm{P}$, Ref. $2 ; \mathrm{F}_{3} \mathrm{P}-\mathrm{BH}_{3}$, Ref. 4; $\mathrm{F}_{3} \mathrm{P}$, Ref. 10; $\mathrm{HF}_{2} \mathrm{PO}$, Ref. 3 . All parameters were determined by microwave spectroscopy except those of $\mathrm{F}_{3} \mathrm{P}$, which were determined by electron diffraction.

density to the $\mathrm{P}-\mathrm{B}$ bond. However, since the $\mathrm{P}-\mathrm{B}$ bond length does not reflect more convincingly the stability difference, this is probably not the entire explanation. Several additional effects can be suggested. (1) The tilt of the borane group presumably increases the stability of $\mathrm{HF}_{2} \mathrm{P}-\mathrm{BH}_{3}$ (cf. below). (2) The reorganization energies of $\mathrm{HF}_{2} \mathrm{P}$ and $\mathrm{F}_{3} \mathrm{P}$ due to the small changes in structures upon coordination may favor the formation of $\mathrm{HF}_{2} \mathrm{P}-\mathrm{BH}_{3}$. (3) Since the stability measurements were estimates of equilibrium constants, entropy effects must also be considered although they are expected to be small. Therefore, it appears that there is no single effect which contributes predominantly to the increased stability of $\mathrm{HF}_{2} \mathrm{P}-\mathrm{BH}_{3}$ but that it most likely arises from a combination of effects.

The above discussion assumed that the $\mathrm{P}-\mathrm{B}$ bond is essentially a classical $\sigma$ or dative bond. It can be readily adapted to the alternative proposal forwarded to account for the stability of $\mathrm{F}_{3} \mathrm{P}-\mathrm{BH}_{3}{ }^{14}$ This view, which was postulated because $\mathrm{F}_{3} \mathrm{P}$ does not coordinate to other boron acids such as $\mathrm{BCl}_{3}$, asserts that the $\sigma$ bond is supplemented by $d_{\pi}-p_{\pi}$ bonding between the electrons of the borane group and the phosphorus $d$ orbitals. The $d$ orbitals have been contracted by the three attached fluorines. $\mathrm{By}$ extension to $\mathrm{HF}_{2} \mathrm{P}$ $\mathrm{BH}_{3}$, the hydrogen on the phosphorus causes a decrease in the $\pi$ interaction, but this is compensated for by an increase in the $\sigma$ bond strength due to the electron-releasing property of the hydrogen. This view

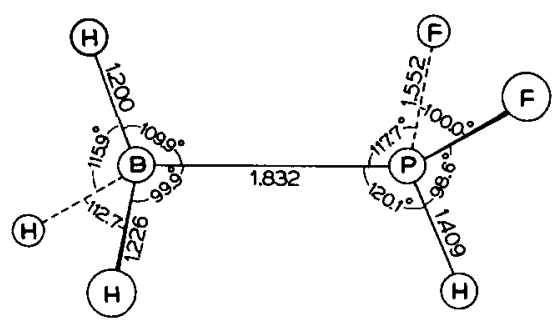

FIG. 2. The structure of difluorophosphine borane. could rationalize the nearly identical P-B bond lengths in the two complexes. ${ }^{15 a}$

The most unusual structural feature of $\mathrm{HF}_{2} \mathrm{P}-\mathrm{BH}_{3}$ is the lack of symmetry of the borane group about the $\mathrm{P}-\mathrm{B}$ bond. This discussion will concentrate on the $\mathrm{PBH}$ angles (Fig. 2) which indicate a pronounced tilt of the borane group away from the fluorine atoms, particularly when compared to the $\mathrm{PBH}$ angle of $\mathrm{F}_{3} \mathrm{P}-\mathrm{BH}_{3}\left(103^{\circ}\right)$. While tilted methyl groups have been observed in several compounds, the effect was less pronounced and was usually observed when the methyl group was adjacent to a nonbonded electron pair or a carbonyl group. ${ }^{16}$ In fact, a tilt has not been reported in isoelectronic $\mathrm{HF}_{2} \mathrm{Si}-\mathrm{CH}_{3}$ which otherwise has structural features ${ }^{17}$ very similar to those of $\mathrm{HF}_{2} \mathrm{PBH}_{3}$.

Since it has been suggested that the classical $\sigma$ or dative bond of $\mathrm{F}_{3} \mathrm{P}-\mathrm{BH}_{3}$ is supplemented by $d_{\pi}-p_{\pi}$ bonding between the electrons of the borane group and phosphorous $d$ orbitals, ${ }^{14}$ extended Hückel molecular-orbital (EHMO) calculations were made to determine whether such a bonding mechanism could account for the tilt. Computations were made as a symmetric borane group (i.e., equal $\mathrm{BH}$ bonds and $\mathrm{HBH}$ angles) was tilted about the $\mathrm{PB}$ bond, using EHMO recipes obtained from Bartell et al. ${ }^{15 \mathrm{~b}}$ The energies were noticeably improved by including $d$ orbitals; however, a minimum energy was obtained for a structure in which the borane group was coaxial about the $\mathrm{P}-\mathrm{B}$ bond. The calculations indicated that the observed tilted configuration should be less stable by $0.4-0.8 \mathrm{kcal} / \mathrm{mole}$ depending upon the choice of orbital coefficients or ionization energies. This deformation energy is of the order expected for a $\mathrm{BH}_{3}$ rocking motion by analogy with force constants of other molecules. Therefore, this MO calculation gave no support for a bonding mechanism as the origin of the tilt although the approximations in the calculation do not eliminate it completely.

In order to account for the observed tilted borane group by other approaches, it seemed unlikely that arguments based entirely upon steric or van der 
Waals' interactions would suffice, since structurally similar $\mathrm{HF}_{2} \mathrm{Si}-\mathrm{CH}_{3}$ does not exhibit a pronounced tilt. However, interactions which may account for the structural difference between the two molecules are nonbonded electrostatic effects, which are not explicitly included in EHMO calculations. In particular, the hydrogens bonded to boron are more hydridic than those bonded to carbon; the hydrogen bonded to phosphorus is more protonic than that bonded to silicon. In other words, in $\mathrm{HF}_{2} \mathrm{P}-\mathrm{BH}_{3}$ the negative fluorines and protonic hydrogen bonded to phosphorus could interact with the hydridic hydrogens bonded to boron to tilt the borane group away from the fluorines. Electrostatic calculations for a symmetrical and tilted borane group placing plausible charges (from the EHMO calculations) or bond dipoles on the terminal atoms support this argument. These calculations gave interaction energies which are consistent with estimates of the magnitude necessary (e.g., 0.4$0.8 \mathrm{kcal} /$ mole from the EHMO calculation) to tilt the borane group by the observed amount. While the meaning of this sort of calculation is open to a measure of skepticism, nevertheless, it appears that a nonbonded electrostatic interaction is the most plausible mechanism for the origin of the tilt. A normal coordinate analysis for $\mathrm{HF}_{2} \mathrm{P}-\mathrm{BH}_{3}$ and investigations of other borane adducts should provide additional information to test this suggestion.

Another interesting result is the high barrier to internal rotation of $\mathrm{HF}_{2} \mathrm{P}-\mathrm{BH}_{3}(3.6-4.5 \mathrm{kcal} / \mathrm{mole})$ compared to that of $\mathrm{HF}_{2} \mathrm{Si}_{-}-\mathrm{CH}_{3}(1.25 \mathrm{kcal} / \mathrm{mole}),{ }^{18}$ particularly since the central bond lengths of these two molecules are essentially identical. This behavior is analogous to that observed in $\mathrm{F}_{3} \mathrm{P}-\mathrm{BH}_{3}(3.24 \mathrm{kcal} /$ mole $)^{4}$ and $\mathrm{F}_{3} \mathrm{Si}-\mathrm{CH}_{3}(1.39 \mathrm{kcal} / \mathrm{mole}) .{ }^{19}$ It seems unlikely that an electrostatic effect similar to that proposed for the tilt is the origin of the high barrier since an estimate of the dipole-dipole interaction energies gave a small value (less than $0.5 \mathrm{kcal} / \mathrm{mole}$ ). In another approach, the model of Lowe and Parr, ${ }^{20}$ which attributes the barrier to the repulsion of partially shielded terminal nuclei $\left(\Delta V_{N N}\right)$, also gave a small barrier of about $1.0-1.5 \mathrm{kcal} / \mathrm{mole}$. On the other hand, the EHMO calculations produced a more realistic barrier value of about $3.8 \mathrm{kcal} / \mathrm{mole}$. Unfortunately, the EHMO calculations do not directly provide insight into the detailed mechanism and a rationale for the high barrier remains to be offered.

Finally, a bond dipole moment model predicted the value and orientation of the dipole moment reasonably well. The bond moments were based upon the observed dipole moments of $\mathrm{F}_{3} \mathrm{P},{ }^{21} \mathrm{PH}_{3}{ }^{22}$ and $\mathrm{F}_{3} \mathrm{P}-\mathrm{BH}_{3}{ }^{4}$
The $\mathrm{BH}_{3}$ group moment was assumed to be colinear with the $\mathrm{P}-\mathrm{B}$ bond in $\mathrm{HF}_{2} \mathrm{P}-\mathrm{BH}_{3}$. This procedure gave a value of $2.39 \mathrm{D}$ at an angle of $22.87^{\circ}$ with the $\mathrm{P}-\mathrm{B}$ bond in good agreement with the experimental values (see Fig. 1).

\section{ACKNOWLEDGMENTS}

The authors wish to express appreciation to Harvey Schiller, who generously aided in the synthesis of various isotopes, and to Virginia Dunning for permission to discuss her vibrational analysis prior to publication. Stimulating discussions with Dr. R. W. Rudolph and Dr. L. S. Bartell are also acknowledged.

* This research was supported by a grant (GP11388) from the National Science Foundation, Washington, D.C.

${ }^{1}$ R. W. Rudolph and R. W. Parry, J. Am. Chem. Soc. 89, 1621 (1967).

2 R. L. Kuczkowski, J. Am. Chem. Soc. 90, 1705 (1968); R. W. Rudolph and R. W. Parry, Inorg. Chem. 4, 1339 (1965).

${ }^{3}$ L. F. Centofanti and R. L. Kuczkowski, Inorg. Chem. 7, 2582 (1968); L. F. Centofanti and R. W. Parry, ibid. 7, 1005 (1968).

${ }^{4}$ R. L. Kuczkowski and D. R. Lide, Jr., J. Chem. Phys. 46, 357 (1967); R. W. Parry and T. C. Bissot, J. Am. Chem. Soc. $78,1524(1956)$

${ }_{5}^{5}$ R. W. Rudolph and H. W. Schiller, J. Am. Chem. Soc. 90, 3581 (1968).

${ }^{6}$ P. C. Maybury and W. S. Koski, J. Chem. Phys. 21, 742 (1953)

7 J. S. Muenter, J. Chem. Phys. 48, 4544 (1968).

8 J. Kraitchman, Am. J. Phys. 21, 17 (1953).

$9 \mathrm{~V}$. Dunning (private communication).

${ }^{10} \mathrm{Y}$. Morino, K. Kuchitsu, and T. Moritani, Inorg. Chem. 8, 867 (1969).

${ }^{11}$ R. J. Gillespie, J. Chem. Educ. 47, 18 (1970).

${ }^{12}$ H. A. Bent, J. Inorg. Nucl. Chem. 19, 43 (1961).

${ }_{13}$ D. W. J. Cruickshank, J. Chem. Soc. 1961, 5486.

${ }^{14}$ W. A. G. Graham and F. G. A. Stone, J. Inorg. Nucl. Chem. 3, 164 (1956).

15 (a) Bartell and $\mathrm{Su}$, employing extended Hückel $\mathrm{MO}$ calculations, have also pointed out that $\mathrm{HF}_{2} \mathrm{P}$ and $\mathrm{F}_{3} \mathrm{P}$ behave anomalously.15b They showed that the bonded overlap populations normally increased when more electronegative groups were attached to phosphorous except in the case of the PO overlaps in $\mathrm{HF}_{2} \mathrm{PO}$ vs $\mathrm{F}_{3} \mathrm{PO}$. The EHMO calculations by us on $\mathrm{HF}_{2} \mathrm{P}-\mathrm{BH}_{3}$ and $\mathrm{F}_{3} \mathrm{P}-\mathrm{BH}_{3}$ resulted in a slightly greater $\mathrm{P}-\mathrm{B}$ bond overlap population for $\mathrm{HF}_{2} \mathrm{P}-\mathrm{BH}_{3}$ vs $\mathrm{F}_{3} \mathrm{PBH}_{3}(<1 \%)$. In contrast to the mechanism suggested in the text, the $\sigma$ and $\pi$ contributions in both molecules were essentially the same. (b) L. S. Bartell, S. L. Su, and H. Yow, Inorg. Chem. 9, 1903 (1970).

${ }^{16} \mathrm{~L}$. Pierce, R. G. Hayes, and J. F. Beecher, J. Chem. Phys. 46,4352 (1967)

${ }^{17}$ L. C. Krisher and L. Pierce, J. Chem. Phys. 32, 1619 (1960). These authors assumed that the $\mathrm{CH}_{3}$ group was symmetric in $\mathrm{HF}_{2} \mathrm{Si}-\mathrm{CH}_{3}$. We found that their data can also accommodate a slight tilt $\left(\sim 3^{\circ}\right)$ of the $\mathrm{CH}_{3}$ group away from the fluorines. However, the smallness of the effect and consideration of experimental error and vibrational effects make this interpretation less firm than in $\mathrm{HF}_{2} \mathrm{P}-\mathrm{BH}_{3}$.

18 J. D. Swalen and B. P. Stoicheff, J. Chem. Phys. 28, 671 (1958)

${ }^{19}$ B. Kirtman, J. Chem. Phys. 37, 2516 (1962).

${ }^{20}$ J. P. Lowe and R. G. Parr, J. Chem. Phys. 44, 3001 (1966).

${ }_{21}$ R. G. Shulman and B. P. Dailey, Phys. Rev. 78, 145 (1950).

${ }_{22}$ C. A. Burrus, J. Chem. Phys. 28, 427 (1958). 